\title{
PROCESSO BIM EM EDIFICAÇÃO DE CONTAINERS REAPROVEITADOS
}

\section{BUILDING BIM PROCESS USING REUSED CONTAINERS}

\section{Paula Letícia Tissei (UFPR); \\ Helena Fernanda Graf, M.Sc. (UNILA); \\ Henrique José Silva de Carvalho, M.Sc. (UFPR); \\ Sérgio Scheer, Dr. (UFPR)}

\section{Palavras Chave}

Containers; Modelagem; Reaproveitamento; BIM

\author{
Key Words \\ Containers; Modeling; Reuse; BIM
}

\section{RESUMO}

O setor da construção civil possui alto consumo de materiais e geração de resíduos e, consequentemente, impacta o ambiente. A partir desse contexto, o trabalho apresenta a reutilização de containers como residência. Essa tecnologia ainda é pouco utilizada no Brasil pela necessidade de mão de obra especializada, mas, seu uso está se expandindo. Permite o feitio de uma obra mais rápida, limpa e menos impactante que o método convencional. Esses aspectos vão de encontro aos da tecnologia da Modelagem da Informação da Construção ou Building Information Modeling - BIM. A partir desses conceitos buscou-se desenvolver uma forma de modelar a edificação de containers através do processo BIM. Foram trabalhados os elementos e partes do container, de forma a permitir a modelagem da edificação, assim como, elementos construtivos adicionais que permitiram a projetação para esse tipo de construção. A modelagem da edificação com uso de containers inclui informações de especificação da modelagem em seus elementos. Algumas dificuldades no processo foram encontradas e as soluções adotadas são apresentadas no corpo do artigo. Faltam componentes específicos para esse sistema e existe a necessidade de expansão de pesquisas nessa área uma vez que nem todos os sistemas e tecnologias construtivas são contemplados no BIM.

\section{ABSTRACT}

The construction sector has high material consumption and waste generation and consequently impacts the environment. From this context, the paper presents the reuse of containers as a residence. This technology is not widely used in Brazil by the need for skilled labor, but its use is expanding. It allows a faster, cleaner and less impacted work if compared to the conventional method. These aspects are according to technology Building Information Modeling - BIM. From these concepts, we sought to develop a way to model the building of containers through the BIM process. Elements and parts of the container has worked, in order to allow modeling of the building, as well as additional elements that allowed make project for this type of construction. The modeling of container's building includes modeling specification information into its elements. Some difficulties were encountered in the process and the solutions adopted are presented in the paper. There are not enough specific components and a need expanding research exists in this area, because not all construction systems and technologies are contemplated into BIM. 


\section{INTRODUÇÃO}

O setor da construção civil consome matéria prima em abundância, além de gerar grande quantidade de resíduos, o qual interfere diretamente no ambiente. Impactos ambientais de edificações ao longo do seu ciclo de vida são reconhecidos como um sério problema para a indústria da construção (POLSTER et al, 1996).

$\mathrm{Na}$ atualidade, a busca pela sustentabilidade na construção civil está crescendo em função das necessidades ambientais, porém, a mesma é restrita pela capacitação de mão-de-obra no Brasil. Por isso, o crescimento dessa visão não cresce significativamente se comparado a outros países (CORBAS, 2011).

Em busca de reduzir os impactos no meio ambiente, é necessário desenvolver projetos e novas tecnologias que utilizem materiais ambientalmente corretos, ou seja, que visam minimizar os resíduos. Uma solução para reduzir essa quantidade de resíduos da construção é a utilização de containers como peça estrutural da residência. Esses containers também prejudicam o ambiente, pois, os mesmos são utilizados para o transporte de cargas e, após um período de aproximadamente dez anos, devem ser renovados e, então, são descartados sem perspectiva de reciclagem, gerando problemas ambientais.

Portanto, a utilização dos containers para a construção, além de eliminar os problemas causados com a geração de resíduos de construção, também diminui os impactos causados pelo descarte dos containers que não trabalham mais como transportadores de carga.

Através da Modelagem da Informação da Construção é possível desenvolver modelos virtuais da edificação em nível de projeto executivo desde o início da concepção arquitetônica. No entanto, as ferramentas/softwares existentes conservam o modo tradicional de construir. Ao fugir do convencional, o projeto com uso de containers necessita de uso diferenciado das ferramentas para permitir a modelagem da edificação. Dessa forma, o presente trabalho teve como objetivo apesentar um processo de modelagem para projetos com estrutura de containers. Foi desenvolvido um projeto arquitetônico através do conceito da Modelagem da Informação da Construção (ou, do inglês, Building Information Modeling - BIM).

\section{CONTAINERS E SUSTENTABILIDADE NAS CONSTRUÇÕES}

Os containers são caixas metálicas de dimensões padronizadas internacionalmente, que tem como objetivo principal o transporte de cargas em seu interior, através de navios, trens ou até caminhões. O processo de transporte através de containers foi criado em meados dos anos 50 , pelo inventor Malcolm McLean, com a finalidade de substituir o carregamento de navios por estivadores. Porém, a vida útil de um container é de 7 a 10 anos, sendo, após, inutilizável, levando-o a diversos destinos. Na maioria das vezes é descartado junto a uma "montanha" de caixas metálicas abandonadas e não biodegradáveis nas cidades portuárias (PORTAL METÁLICA, 2012).

Conforme o arquiteto Danilo Corbas (2011), o uso de containers como uma alternativa na construção civil torna a obra mais limpa, ágil e sustentável.

John et al. (2000) identificou as principais prioridades em termos de sustentabilidade no Brasil e propõem uma Agenda Nacional que incluiu a redução de perdas de materiais de construção, desperdícios com reciclagem de resíduos da indústria da construção civil, melhoria na eficiência energética de edificações e do processo construtivo, durabilidade/manutenção da construção, infraestrutura, saneamento, conservação da água e qualidade do ar interior.

No Brasil, a construção com aplicação de critérios de sustentabilidade é influenciada por grandes desafios como déficit habitacional, infraestrutura para o transporte, comunicação, abastecimento de água, saneamento básico, energia, atividades comerciais e industriais (DEGANI, 2010).

Para o meio ambiente, esses containers abandonados são grandes poluidores (Figura 1). O mesmo pode-se considerar para os materiais da construção civil, os quais originam diversas caçambas de entulhos durante o período de obra. Portanto, a reutilização desses containers como substituição de materiais para a construção, elimina o alto consumo de cimento e tijolos. Ou seja, diminui-se em grande quantidade o "cemitério" de caçambas e, por consequência, o problema com resíduos de obras civis.

Figura 1: Containers inutilizáveis ao lado do Porto de Santos

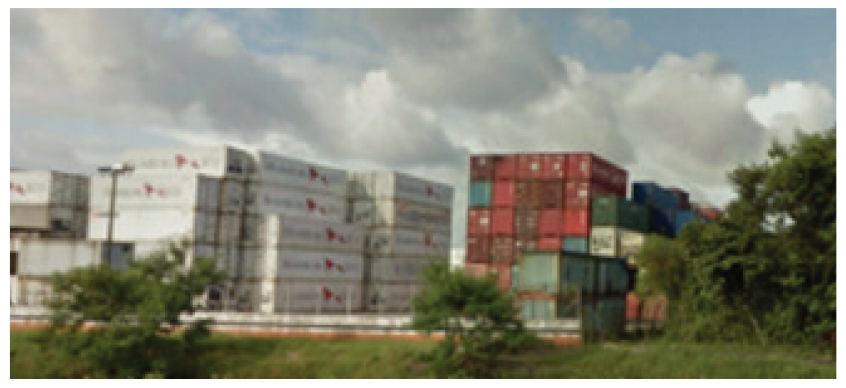

Fonte: Oliveira, 2013

Recentemente, organizações como a LOT-EK e Numen Development, e arquitetos como o australiano Sean 
Godsell e o americano Adam Kalkin, colocaram em prática essa nova ideia de reutilização de container nos projetos de residência, ou seja, as casas-container. Atualmente, o potencial de execução de obras com essas caixas de aço está se expandido rapidamente para a arquitetura residencial, porém, ainda encontra pouco espaço no Brasil, no que se refere à mecanização, pré-fabricação e mão-de-obra (ZOMER, 2009).

No Brasil, a utilização de containers como residência ainda não é muito comum, mas, já se utiliza muito para espaços temporários como: exposição, feiras, postos policiais, canteiros de obras, entre outros (Madeira, 2013). As estruturas de aço são resistêntes, porém, leves e possuem um perfeito encaixe entre elas. Na construção civil, elas precisam ser modificadas para obter visual agradável e conforto térmico.

\section{PARTICULARIDADES DE UMA CASA -CONTAINER}

Um projeto de casa-container pode ser executado conforme as necessidades do consumidor. Podendo ser utilizada uma ou mais dessas estruturas de aço para a construção da residência. Para a legislação de construção e obras dos municípios as casas-container caracterizam-se como casas populares em estruturas metálicas.

Existem três tamanhos padrões de containers e os mesmos podem ser encaixados conforme o necessidade de projeto. Há ainda o container refrigerado que possui a vantagem de já possuir isolamente térmico. No entanto, o custo deste chega a ser o triplo se comparado a um container marítimo e é complicado encontrá-los a venda (CORBAS, 2011).

O container já é a estrutura em da casa. Consegue ficar estável com até $2 / 3$ da sua estrutura em balanço, sendo ancorado nas suas pontas pelo encaixe existente. É possível criar áreas cobertas utilizando a própria estrutura de metal (CORBAS, 2011).

Com relação às instalações prediais, os sistemas hidráulico e elétrico são idênticos ao de uma construção comum, embutido na parede (internamente ao isolamento), porém, não se obtém desperdício de material com a quebra dos blocos cerâmicos para a inserção da tubulação.

\subsection{Exemplos de utilização de containers na construção civil}

O Museu Nomadic (Figura 2) construído para abrigar uma exposição de fotografia em Nova York, em 2005, foi desmontado e remontado em Santa Monica, Califórnia, EUA, no início de 2006.

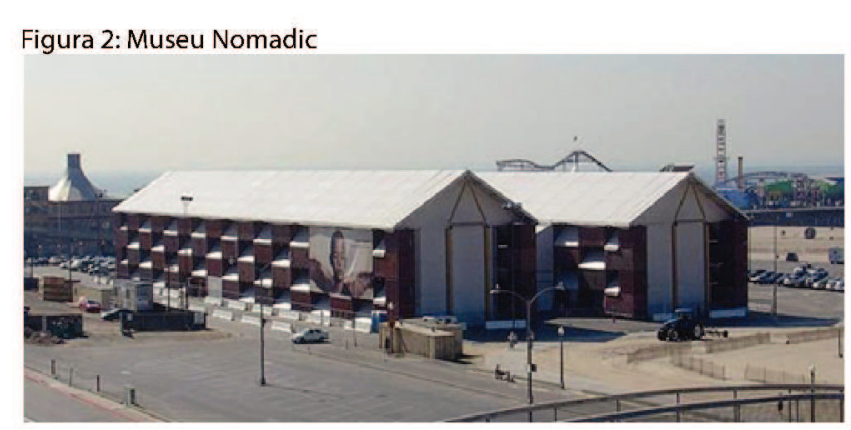

Fonte: Portal Metálica, 2012

Outro exemplo é a Container City localizado na Inglaterra, na região portuária de Docklands. A edificação construída em no ano 2000 é um conglomerado de containers usados como acomodações modulares, que demorou 5 meses para ser finalizada, tendo utilizando um total de 20 containers (Figura 3 ).

Figura 3: Projeto Container City

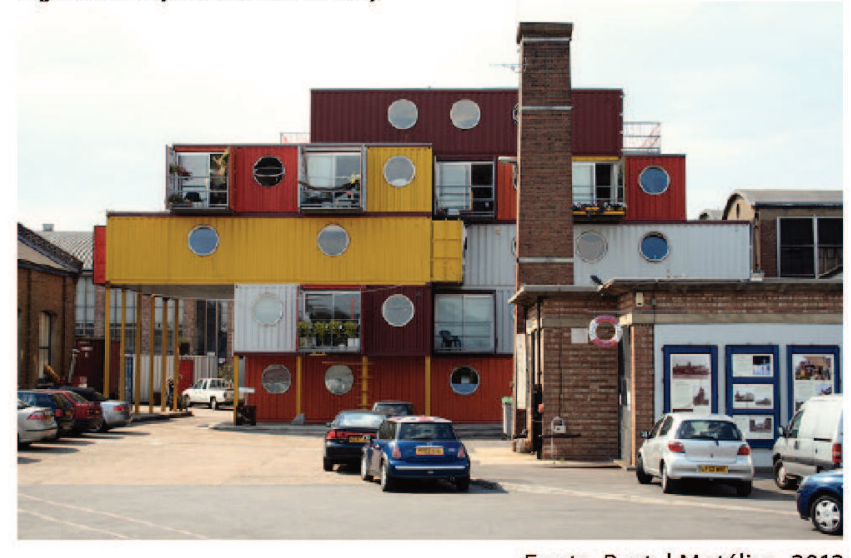

O México também aderiu à ideia de construir uma "Container City", tornando-se uma das principais atrações turísticas na cidade de Cholula (Figura 4). Foi idealizado pelo designer gráfico Gabriel Esper Caram, o local possui $5.000 \mathrm{~m}^{2}$, sendo composto por 50 containers marítimos. Esse projeto não se aplicou apenas para residências habitacionais, mas também foram construídos bares, lojas, livrarias, galerias de arte, restaurantes, padarias e até hotéis.

Figura 4: Container City México

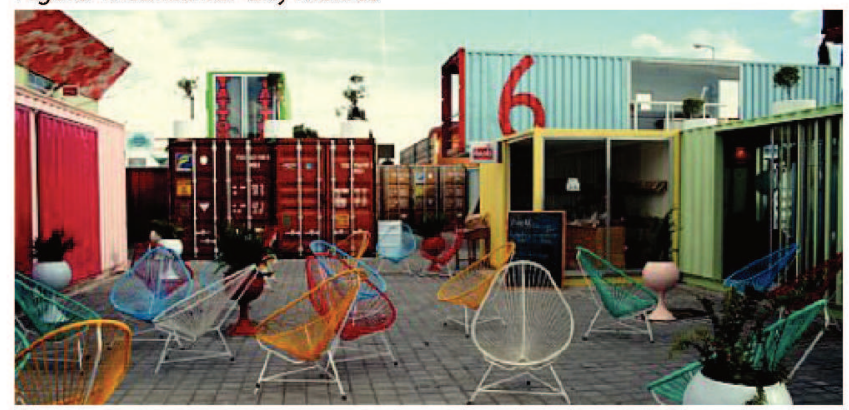

Fonte: Portal Metálica, 2012 
A Redondo Beach House (Figura 5), no sul da Califórnia é um outro bom exemplo de projeto executado com o uso de containers (PORTAL METÁLICA, 2012).

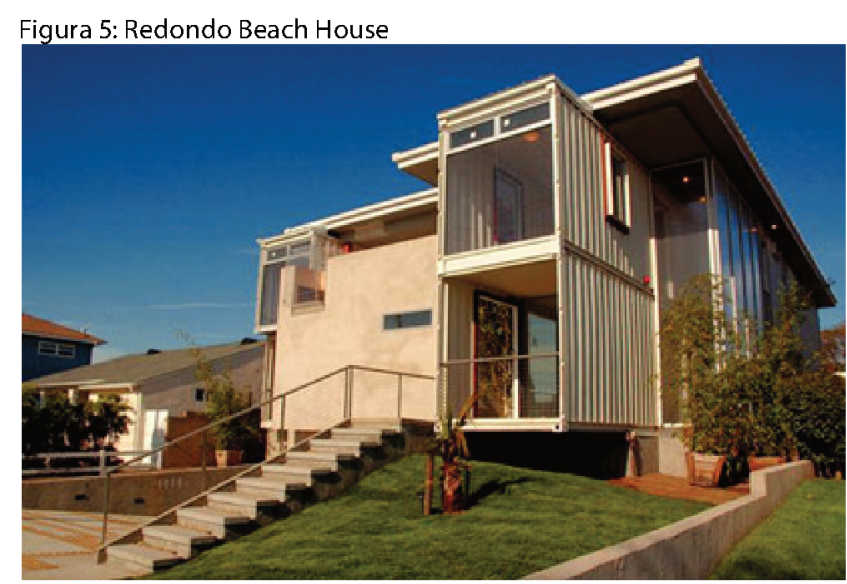

Fonte: Portal Metálica, 2012

\section{PROJETO E MODELAGEM}

Após definição do terreno e levantamento planialtimétrico do mesmo, foram feitos estudos volumétricos para a definição da forma da edificação e composição com containers (Figura 6). Inicialmente foram estudados os volumes com elementos de papelão criados manualmente, para em seguida serem modeladas com o uso do software Revit Architecture, que trabalha através da plataforma Building Information Modeling. Esse processo permite simular, através de um modelo, as informações do edifício. Através deste conceito, é possível identificar os possíveis problemas de projeto e corrigi-los de forma que o erro não chegue ao local da obra.

Figura 6: Estudo volumétrico

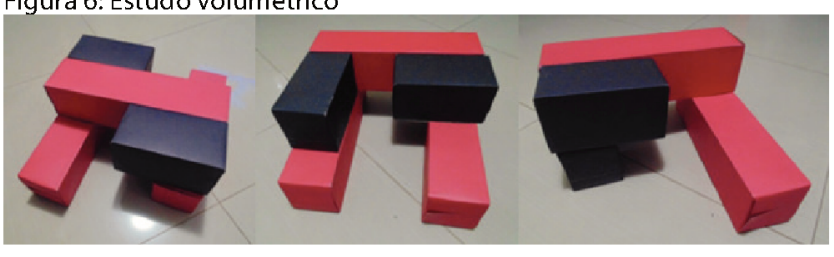

Fonte: Elaborado pelos autores

Para a modelagem, houve algumas dificuldades com relação à utilização do Revit, pois, o projeto não é um modelo convencional. Porém, ainda assim, o uso da ferramenta simplificou expressivamente o tempo e identificações de problemas se comparado aos métodos convencionais. A residência é composta de dois pavimentos e faz uso de cinco containers de dois tamanhos diferentes. Nas Figuras 7, 8 e 9 é possível fazer a leitura do projeto.
Figura 7: Plantas dos pavimentos (térreo à esquerda e superior à direita)
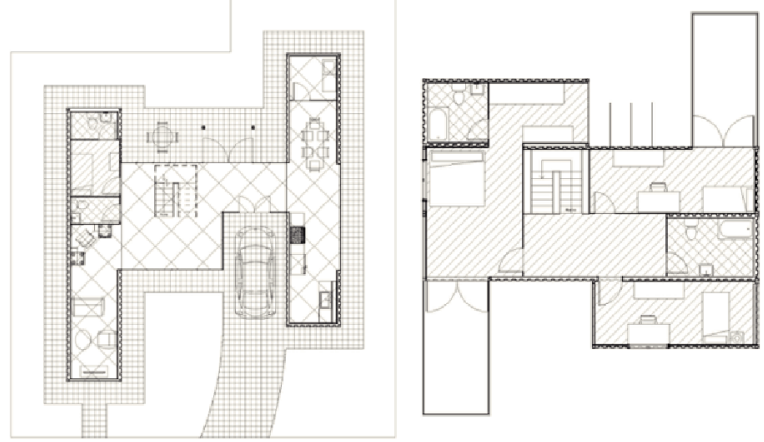

Fonte: Elaborado pelos autores

Figura 8: Elevações (da esquerda para a direita, leste e norte acima, oeste e sul a baixo)
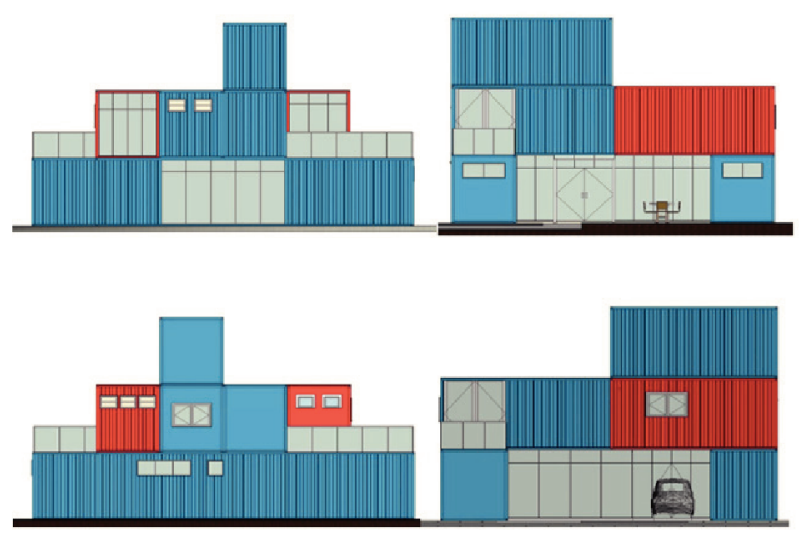

Fonte: Elaborado pelos autores

Figura 9: Perspectivas
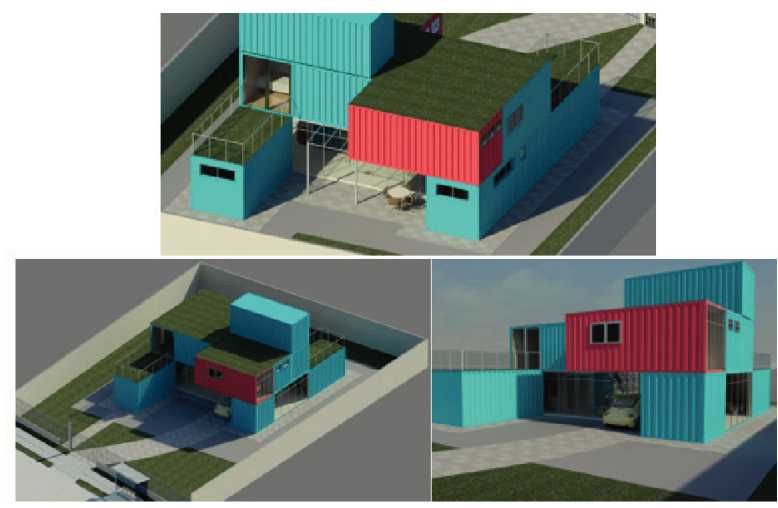

Fonte: Elaborado pelos autores

\subsection{Recorte de janelas e portas}

Após a definição dos encaixes dos containers, os mesmos são avaliados quanto aos recortes a serem feitos para a implantação das janelas, portas e aberturas. Os recortes são executados por empresa especializada conforme definido no projeto, bem como, as soldas, molduras, correções do container em relação aos amassados, danificações devido ao seu período de serviços com transporte de cargas, limpeza e pintura anticorrosiva.

Na modelagem, devido ao fato da estrutura do container não obter uma superfície plana, ao inserir portas e 
janelas, erros eram indicados, pois, o perfil dessas aberturas não coincidia com a estrutura da parede do container (com reentrâncias). Foram obtidas duas soluções.

A primeira solução (Figura 10) foi dada através da inserção de uma parede comum (1), porém, com o mesmo material da parede container (aparentando ser a moldura da janela) e mais espessa de forma que esta parede ultrapassasse a parede do container (5) e a parede interna de drywall (2). Criando essa parede, foi executado o corte de geometria da mesma para as paredes do container (4) e a parede de drywall (2), porém, as paredes de container (5) não são paralelas à parede que está cortando, então, foi executado o processo de editar perfil em cada face da parede inclinada. Por fim, inseriu-se a parede cortina (3) dentro da parede de auxílio (1).

Figura 10: Corte de geometria e parede cortina

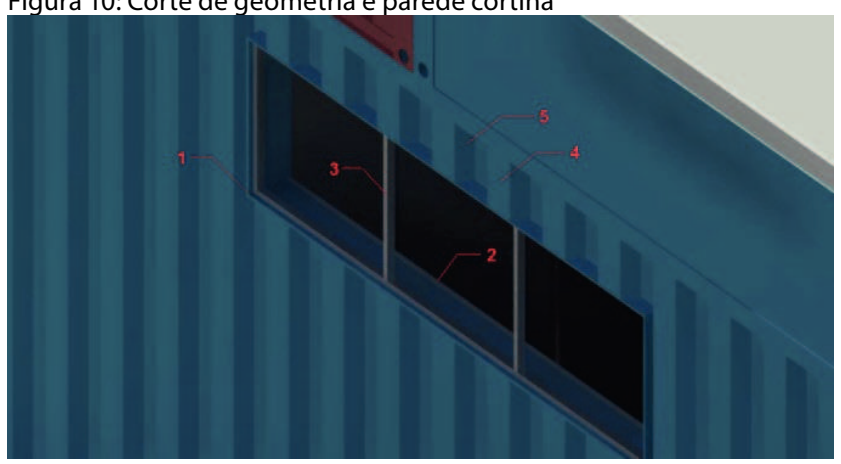

Fonte: Elaborado pelos autores

A segunda solução (Figura 11) visa editar o perfil de cada face da parede do container ( 2 e 3) que cruza a janela, inclusive a parede interna de drywall (5) criando-se uma abertura. Então, insere-se uma parede para auxílio espessa (1) do mesmo material que o container que atravesse as duas superfícies (aparentando ser a moldura da janela) e por fim adiciona-se uma janela (4) na parede de auxílio (1).

Figura 11: Edição de perfil

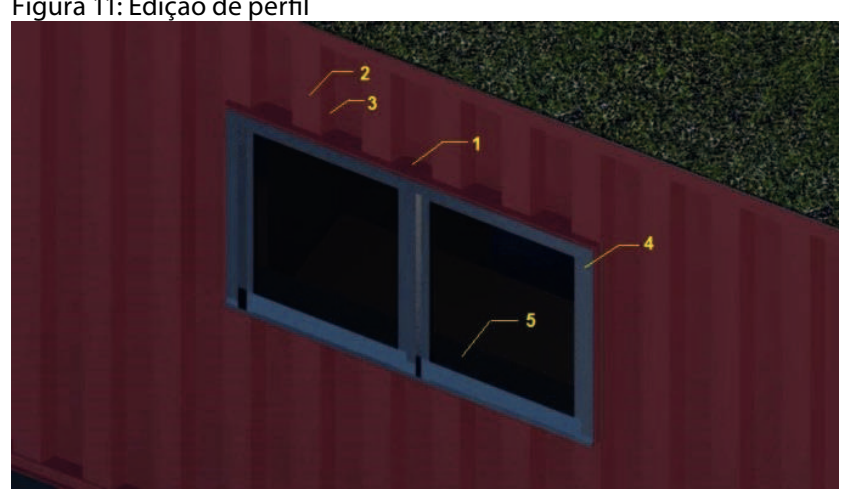

Fonte: Elaborado pelos autores

Nessa etapa são importantes os detalhes e dimensões dos cortes, os quais não pode haver erros, pois, impossibilita as correções no local da obra. Uma vez que o BIM trabalha com a simulação da construção, com todos os componentes e detalhes destrutivos, faz-se necessário tais cuidados. Os recortes para este projeto são enviados em plantas para a empresa especializada. Os containers foram numerados (Figura 12) e, posteriormente, feito o projeto de cortes e aberturas dos containers individualmente, como é possível ver um exemplo na Figura 13.

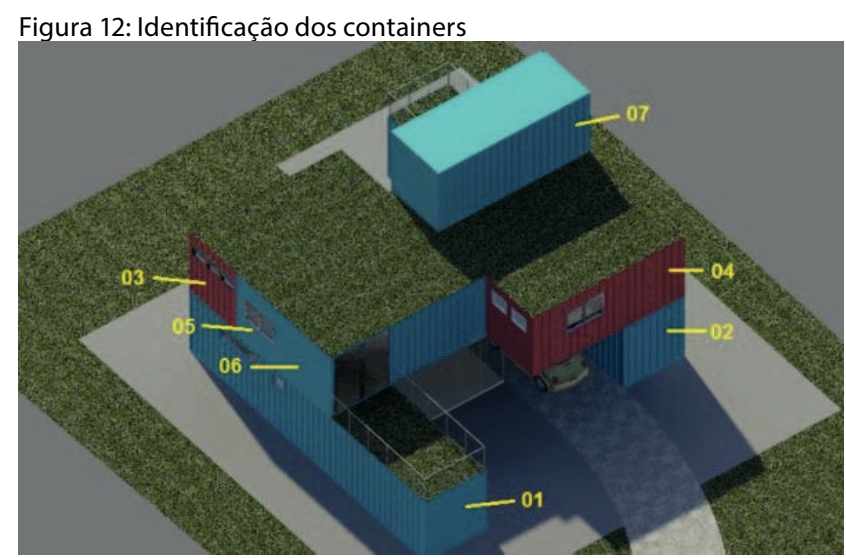

Fonte: Elaborado pelos autores

Figura 13: Projeto de cortes e aberturas

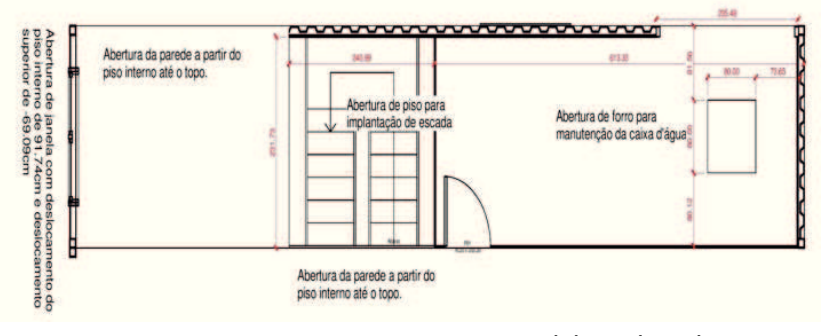

Fonte: Elaborado pelos autores

A fundação é uma etapa que pode ocorrer em paralelo aos recortes. Devido à estabilidade do container, não é necessária uma implantação de fundações profundas. Portanto, para o projeto é utilizada uma fundação do tipo radier armado.

A montagem pode ser executada em apenas um dia, conforme o arquiteto Danilo Corbas (CORBAS, 2011). Os módulos chegam ao local por caminhões e são encaixados com a ajuda de guindastes. Esses containers são ancorados entre si e formam esqueleto estrutural do projeto. Assim, a casa está montada, sem nenhuma utilização de alvenaria ou outros materiais relacionados.

No modelo foi utilizada Lã de PET como isolante térmico e acústico. Para o projeto foi utilizado o comando massa no local e identificado onde deve haver esse isolamento. Também foi inserido este isolamento em paredes onde passam tubos hidráulicos e elétricos, para eliminar o ruído causado pelas tubulações junto ao metal. 
Figura 14: Exemplo de acabamento

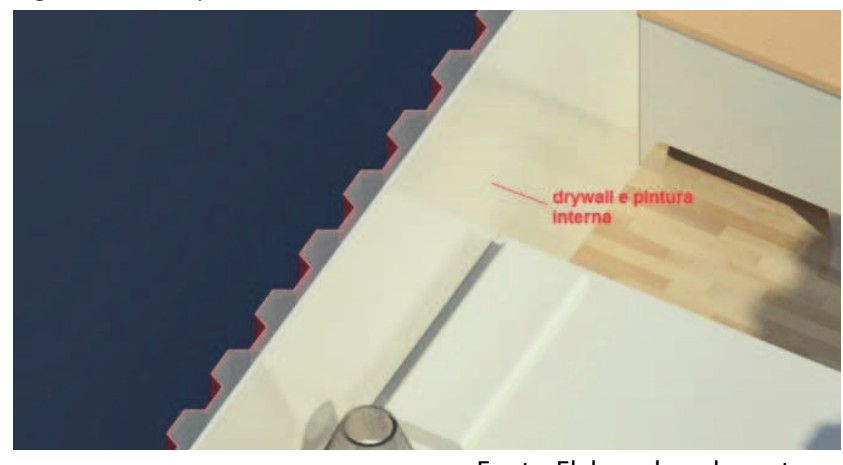

Fonte: Elaborado pelos autores

Optou-se pela utilização de gesso acartonado para a implantação das paredes (lado interno) e forros, devido à sua praticidade, rapidez e geração de poucos resíduos ao final desta etapa. As placas de drywall são um material resistente à compressão e à maleabilidade e possui uma pequena espessura, sem diminuir muito os espaços da residência. Posteriormente, é aplicada a pintura no drywall. A estrutura do container é de aço, porém, internamente foi projetada para que não ocorra tal percepção, mantendo o ambiente agradável e sem o visual do container (Figura 14).

Para os banheiros ou áreas com bastante umidade, o gesso acartonado comum não é recomendado e utiliza-se o modelo de chapa de cor verde (chapa resistente à umidade), a qual é utilizada em áreas molhadas. Essas chapas de gesso apresentam silicone na composição, trazendo maior resistência à umidade. Porém, as chapas não podem entrar em contato com a água, pois, infiltrações podem danificar o gesso.

Nos banheiros e na área de serviço a pintura foi aplicada somente no forro, pois, nas paredes serão utilizados azulejos como acabamento, diminuindo o contato de umidade com o gesso. Na cozinha a pintura é aplicada em todas as superfícies.

Não há uma restrição para a utilização dos pisos para esse tipo de projeto. É aplicado igualmente à alvenaria convencional. Painéis de vidros são fixados na estrutura do container, mantendo as paredes de drywall na área interna da residência.

A cobertura é com telhado verde (vegetação). Esse telhado se encarrega de dissipar ou consumir a energia do calor pela evapotranspiração e pela fotossíntese, reduzindo expressivamente a amplitude térmica do interior da residência (SILVA, 2012).

Em função do número restrito de páginas, esse item relata a modelagem de forma concisa. No entanto, caso haja interesse, o leitor poderá ver mais detalhes no trabaIho de Tissei (2014).

\section{CONCLUSÕES}

O presente trabalho abordou a reutilização dos containers descartados para servir como estrutura em um projeto residencial visando à reciclagem dos mesmos e a redução de resíduos de construção civil.

O processo projetual utilizado empregou a Modelagem da Informação da Construção. Como as ferramentas/softwares não são feitos para projeto com containers, o desafio era usar o Revit Architecture para construir um modelo virtual BIM com esses elementos. Especificidades como as reêntrancias das faces do container necessitaram de alternativas para serem modeladas, não apenas como modelo virtual, mas, como modelo com informações. Essas informações de projeto exigem a correta modelagem para a geração de quantitativos, compatibilidade com as instalações prediais e fundação, bem como a documentação e desenhos técnicos precisos para os cortes para aberturas.

Formas foram estudadas para o desenvolvimento da modelagem e, dentre elas, duas foram apresentadas nesse trabalho. A Modelagem da Informação da Construção é uma plataforma útil para diferentes tipos de projetos e sistemas construtivos, mas, em vezes são necessários estudos quanto à melhor forma de uso das ferramentas e comandos.

\section{AGRADECIMENTOS}

Os autores gostariam de agradecer à Universidade Federal do Paraná, ao Grupo de pesquisa TIC e aos profissionais que puderam colaborar com informações e entrevistas.

\section{REFERÊNCIAS}

CORBAS, D. Entrevista com Danilo Corbas. Curitiba, 2011. 12 f. Digitado. Entrevista a Paula Letícia Tissei.

DEGANI. C. M. Modelo de gerenciamento da sustentabilidade de facilidades construídas. Tese (Doutorado em Engenharia de Construção Civil), Escola Politécnica, Universidade de São Paulo, São Paulo, 2010.

JOHN, V. M. Reciclagem de resíduos na construção civil: contribuição para metodologia de pesquisa e desenvolvimento. Tese (Livre Docência), Escola Politécnica, Universidade de São Paulo, São Paulo, 2000.

OLIVEIRA, S. Containers. Arquitetura Sustentável. 2013. Disponível em: <http://sisleinearquitetura.com/tag/casas-containers/>. Acesso em: 29/09/2013. 
POLSTER B. PEUPORTIER B, SOMMEREUX IB, PEDREAL PD, GOBIN C, DURAND E. Evaluation of the environmentally conscious design. Solar Energy, v. 57, n. 3, p. 219-230,1996.

PORTAL METALICA. Container City: Um novo conceito em arquitetura sustentável. Disponível em: <http://metalica.com.br/container-city-um-novo-conceito-em-arquitetura-sustentavel>. Acesso em: 08/09/2013.

SILVA, L. Telhados Verdes ganham terreno nas cidades. Eco-Reporter, Lisboa. Entrevista. 2012. Disponível em: <http:// ecoreporter.abae.pt> Acesso em: 10/05/2014.

TISSEI, Paula Leticia. Orientadora: GRAF, Helena Fernanda. Reuso de containers para fins de habitação: pesquisa exploratória sobre casos existentes e desenvolvimento de projeto para identificação das interferências/incompatibilidades e potencialidades de soluções arquitetônicas. Trabalho Final de Curso (graduação) - Universidade Federal do Paraná, Setor de Tecnologia, curso de Engenharia da Construção Civil. Defesa: Curitiba, 2014.

ZOMER, C.D. O Sol: Caminho para sustentabilidade energética de uma Casa Container. Monografia (Concurso Eco_Lógicas) - Setor Eco_Lógicas, Institudo IDEAL, Florianópolis, 2009. Disponível em: <http://institutoideal. org/ecologicas/wp-content/uploads/2012/08/07-CLARISSA_ZOMER.pdf>. Acesso em: 07/09/2013. 